\title{
SERVICIO PÚBLICO Y REALIDADES ECONÓMICAS: DEL SIGLO XIX AL DERECHO COMUNITARIO EUROPEO ${ }^{1}$
}

\author{
MARCEAU LONG
}

Public service directs us to the concept we have of the State. The natural field of action Duguit assigned to public service left a wide margin for interpretation and evolution, which is indispensable for social inter-dependence. Security and order are indispensable, as well as satisfying basic economic, social and cultural needs. The answer of States and the «international community» to the September 11 attack in New York against terrorism, and also the fear of an increase in violence suggest a return to the Protective State, because it quality is order. Even when, with the rise of civil society, the European Community, and the institutions of the international society, it does not become the only guarantee of public interests, it is so that State that we turn, during globalization, to preserve the social pact to prevent it from tearing apart.

Más de cuarenta años de una carrera iniciada con la Auditoría del Consejo de Estado y terminada con su vicepresidencia me han dado la oportunidad que ha sido para mí un gran honor- de conocer bien los servicios públicos y muchas formas del servicio público. Reales y de gestión real², ante todo en el

\footnotetext{
${ }^{1}$ Este artículo apareció originalmente en el número correspondiente a noviembre-diciembre de 2001 de la Rerue Française de Droit Administratif (RFDA), con el título «Service public et réalités économiques du XIX siècle au droit communautaire». Precedente agradece la amable autorización del autor y del editor Dalloz para publicarlo en estas páginas. Agradece también a la Maison Franco Andine du droit Casa Franco-andina del derecho la selección del artículo y el trámite para la autorización.

${ }^{2}$ Régaliens et de gestion régalienne: la expresión sirve para calificar un poder, un derecho, una gestión, una función, un vínculo, que el Estado establece o ejerce con su propia autoridad. En Francia, el Ministère de l'Énvironnement (ministerio del Medio Ambiente), por ejemplo, puede ser considerado como un ministerio régalien en cuanto negocia directivas, prepara leyes, edita reglamentos, vigila el cumplimiento de los mismos, ejerce misiones de policía y de control, repara los daños cuando no ha podido llevar a cabo una política plena de prevención y de protección del ambiente. La expresión tiene sus raíces en el latín medieval: jura regalia: derechos reales (siglo XII); los derechos inherentes a la monarquía. De allí, el vocablo del derecho antiguo regaile. (Precedente agradece a Elisabeth Lager y a Jean Paul Margot el contenido de esta nota).
} 
Consejo de Estado, por supuesto, alrededor de quince años; en asuntos extranjeros - el ministerio y una embajada-(5 años); la Dirección de la Función Pública (6 años); el Secretariado general para la administración del Ministerio de Defensa (6 años), el Secretariado general de gobierno (8 años). No me atrevo a clasíficar mi presidencia de la Oficina de Radio y Televisión de Francia (ORTF) de octubre 1974 a enero 1975 como parte de este largo período de gestión pública ya que estaba también al servicio de la cultura, de la información, del espectáculo (...), algo muy lejano de lo que había conocido hasta entonces. Como a mis predecesores, el Secretariado general del gobierno me abrió las puertas del sector público: público aún, pero administrado según los métodos de la industria y el comercio. Primero en una sociedad de economía mixta - Air Inter - en la que el sector privado poseía el tercio del capital, y Air France el resto, la SNCF, la Caja de Depósitos, el Crédito Lionés y las cámaras de comercio. Finalmente una sociedad anónima en la que el Estado poseía, en esa época, más del 98\% del capital, Air France, celosa de su independencia frente a ese Estado, cuyo apoyo aunque le imponía restricciones, constituía -con sus propios resultados, los de sus pilotos, ingenieros, y su personal comercial- los elementos capitales de su rango y de su prestigio internacional.

No creí venir a menos, ni traicionar ese pasado, al aceptar, después de haber sobrepasado el límite de edad, la presidencia de una fundación de empresas, independiente de los sindicatos de servicios públicos industriales y comerciales, de sus federaciones, y de su Unión (UNSPIC), y que tenía por objetivo el desarrollo de la gestión delegada del servicio público y su profundización. La gestión delegada de los servicios públicos es en el mundo, particularmente para el Banco Mundial, uno de los grandes modelos, que debemos apoyar en la competencia con modelos anglosajones -especialmente la familia del Built Operate Transfer (BOT)-apoyados por la Private Finance Initiative (PFI), los modelos continentales (alemán, español) y la privatización.

$\mathrm{Al}$ hacerlo en interés de la expansión de concepciones que se remontan a nuestras más antiguas tradiciones jurídicas, permanecemos en la línea del servicio público. La historia del derecho nos hace constatar que la jurisprudencia del Consejo de Estado ha construido los principios del servicio público a partir de concesiones tales como eran y tales como deberían ser: formados en los moldes de concesiones de canales, de ferrocarriles, de agua, de gas, electricidad, en innumerables especies desde hace varios siglos. Pero no dejemos fijada una pieza esencial de nuestro sistema económico y político en los rasgos de una época. No empobrezcamos el servicio público; más bien tratemos de enriquecerlo. Dentro de esta perspectiva, las diferencias que creemos subrayables entre el concepto francés y el concepto comunitario del servicio público resultan relativizadas en justa medida. En el concepto jurídico francés, el Estado es el depositario de la soberanía nacional que pertenece al pueblo y que éste ejerce conforme a la 
Constitución. Ella determina las estructuras de los órganos que aseguran su funcionamiento, la extensión y los límites de los principios del preámbulo de la Constitución. Esta misión del Estado implica inicialmente que dispone del poder público con el fin de poder prescribir, y si es necesario, sancionar. Este fundamento del derecho público se ha sido enriquecido desde que cobró relieve propio el concepto de servicio público: el Estado no puede limitarse a ordenar y a sancionar. Existen en la sociedad necesidades por satisfacer que son comunes a todos, o a una parte de sus miembros; necesidades de toda índole, que varían en el tiempo y el espacio y que, cuando se tornan vitales para la comunidad, son asumidas por la autoridad política. Si reglamentar y sancionar no basta para satisfacerlas, y si la sociedad civil misma no ha tomado la iniciativa, la autoridad toma en sus manos la satisfacción social de la necesidad. Ese es el origen del servicio público, de los servicios públicos.

La función de servicio público «de servicio de interés general que incluye el servicio de interés económico general» ha existido antes de que se hubiesen clasíficado categorías de la misión; el servicio público existía antes de que existieran los « servicios públicos ». Por eso es que el servicio público ha sido construido por la jurisprudencia a partir de las concesiones, contratos por medio de los cuales en el siglo XIX el Estado y las colectividades locales, habiendo definido y organizado la misión y reservándose su control, confían la ejecución a la iniciativa privada (ferrocarriles por ejemplo; después: gas, electricidad y agua...), cuando no se encargan ellos mismos directamente, que era lo que sucedía más a menudo; el Príncipe no disponía, hasta hace dos o tres siglos, de los hombres y de los medios para una gestión directa. A principios del siglo XX, Duguit podía escribir entonces: «El Estado no es, como han querido hacerlo creer y como se ha creído durante algún tiempo, una potencia que da órdenes, una soberanía; es una cooperación de servicios públicos organizados y controlados por los gobernantes (...) El servicio público es un servicio de interés colectivo que crea el lazo social». En la misma época, lo que llamamos las grandes «leyes del servicio público» - igualdad, continuidad, adaptabilidad, neutralidad - eran impuestas por la jurisprudencia. Hoy, el concepto de servicio público está confrontado tanto con la evolución de la sociedad francesa, que ya no es la misma de antes de la primera guerra mundial, como con las exigencias de la Comunidad europea.

\section{El servicio público frente a las evoluciones económicas, sociales e ideológicas}

El último tercio del siglo XX sometió a «examen al servicio público» en el mismo momento en que la construcción comunitaria tenía como efecto minar su substancia. Los servicios públicos conocieron a finales del siglo XIX y hasta mediados del siglo XX un crecimento irresistible. A los servicios públicos reales tradicionales, o de soberanía, se fueron añadiendo los servicios económicos y, des- 
pués, los servicios públicos sociales y culturales. Para llevar a buen término el desarrollo de estos servicios, el grupo de colectividades públicas, y especialmente el Estado, recurrieron, según los sectores y los períodos, a métodos extremadamente diversificados de gestión: a menudo empezaron por la concesión con la gestión directa, la administración de rentas, que habiendo obtenido la personalidad moral recibió el rango de establecimiento público; después se apeló a la sociedad de economía mixta asociando capitales públicos y capitales privados. La historia de la economía mixta es paralela a la del intervencionismo económico de las colectividades locales, y su fortalecimiento data del decreto del 20 de mayo de 1955 que extendió las posibilidades para las colectividades de recurrir a estas estructuras y, sobre todo, de la ley del 7 de julio de 1983 que se traduce en una explosión del número de sociedades de economía mixta, que pasó de 600 en 1983 a 1300 actualmente.

La cultura francesa de una asociación de lo público y privado es el llamado del soberano, del Príncipe, a la unión de sus « leales súbditos» o de sus «buenas ciudades»; desde el despertar de las comunas, para las necesidades de la «conquista del territorio»: desagüe de pantanos, apertura de caminos y de vías, construcción de canales, fuentes públicas, adoquinado de calles, construcción de obras públicas de reforzamiento de puentes y calzadas. El Príncipe, tal y como lo escribió François Rachlinel, fue en primer lugar el «que toma primero» - primum capere -; después, cuando la economía del encantamiento encontró sus límites en el Occidente medieval, el príncipe intensificó su poder y transformó «su territorio en zona productiva, favoreció la creación de mercados, mediante los cuales la soberanía pudo echar mano de las riquezas y quedarse con su parte». Con el tiempo, el soberano se convertiría en productor y empleador; al no poder hacerlo todo, cuando toma la decisión de realizar algo, a menudo confia su ejecución a un operador: es la concesión, sobre el fundamento de la división de responsabilidades entre el que organiza y controla, y el que construye y explota. Al lado de las actividades autorizadas por decisiones del poder público, asistimos al desarrollo de actividades que no siempre gozaban de una investidura clara de servicio público otorgada por la decisión soberana o, en su defecto, por el juez. Es así como se produjo una multiplicación de actividades llamadas «accesorias», que no entraban en el campo de la misión de servicio público pero que constituian sin embargo el complemento natural: ise trataba de servicios públicos? La jurisprudencia con frecuencia ha respondido afirmativamente desde principios del siglo XX, aunque preservando el principio de la libertad de comercio y de la industria de textos de 1791, es decir, poniendo la condición de carencia o insuficiencia de la iniciativa privada.

Desde los años inmediatamente posteriores a la Primera Guerra mundial, la evolución de esta forma de asociación entre poderes públicos y operadores no fue la misma para los servicios nacionales y para los de las colectividades 
locales. La transformación de numerosas concesiones de ferrocarriles, de distribución de la electricidad y del gas en empresas nacionales - SNCF, EDFFDG- dio, con el nacimiento de estos grandes grupos, una forma original al «servicio público». La guerra, la liberación, la reconstrucción, la planeación han hecho de estos monopolios la «punta de lanza» de la renovación de equipos, del nuevo arranque de la economía, de la reducción de las desigualdades sociales en el nuevo paisaje político; ellos se convirtieron en un aspecto del compromiso social que la importancia de los retos y del esfuerzo solicitado al país necesitaba y justificaba, y siguen siendo una de las más preciosas cartas de triunfo en un mundo muy diferente.

Los servicios locales -agua, saneamiento, basuras, energía, transportes- dependen por su parte de un modelo secular renovado por las leyes de la descentralización. Su gestión puede ser delegada, por contrato, para un período frecuentemente largo, a empresas privadas, públicas o de economía mixta; si el contrato de administración es del mismo tipo, el estatuto de explotador según la naturaleza jurídica y la forma de la empresa, tiene en la gestión una incidencia nada menospreciable y que puede transformar la naturaleza de las relaciones especialmente cuando el concesionario - el operador- es empresa pública y monopolio nacional, así como lo demuestran la relaciones entre EDF-GDF o SNCG y las colectividades locales. La Federación nacional de colectividades concesionarias y administradas, queriendo constituirse en administradora privilegiada de estas empresas nacionales, con las que tiene vínculos estrechos, solicitó , para renovar la « economía concesionaria », la renegociación de los contratos de concesión y el establecimiento de nuevos pliegos de condiciones.

¿Es acaso nuestra tradición de servicios locales concedidos la herencia de nuestras concepciones centralizadoras -en cuanto a la tutela sobre estos «menores » que fueron durante largo tiempo colectividades locales y al desmigajamiento de nuestro territorio en 36.000 comunas-, lo que ha sido fermento poderoso para esta asociación? Sea lo que fuere, lo cierto es que para estas colectividades y sus operadores es el acuerdo entre las dos partes lo que define las relaciones: el contrato puede además referirse a convenios de carácter más general, como los pliegos de condiciones y las prescripciones técnicas para cada sector que son esencialmente urbanos -distribución del agua, saneamiento, recolección, selección y reciclaje de las basuras, calefacción urbana, transportes colectivos, incluyendo los transportes escolares, parqueaderos y estacionamientos, restauración colectiva, servicios funerarios.- Pero es cierto que estos contratos y convenios deben en primer lugar respetar las leyes y sus decretos de aplicación que han intervenido en numerosos sectores. Es conveniente mencionar el ejemplo significativo del sector de las basuras en el que las colectividades locales y los operadores privados están obligados, para la localización y la explotación de las plantas de incineración, a tomar decisiones compatibles con los planes departamentales de eliminación de los desechos domésticos y similares. 


\section{El «servicio público sometido a proceso»}

A pesar de su éxito, o a causa de él, el servicio público ha sido objeto de críticas de diverso orden, al punto que se ha llegado a hablar de «servicio público sometido a proceso». En el plano económico, ante todo, se levantan protestas: ies legítimo reservar algunas actividades para el servicio público, quitándoselas al mercado, partiendo de un uso abusivo de la idea de monopolio natural, o de tarifas poco favorables a ciertas categorías de consumidores? Otras protestas se refieren al peso excesivo del recurso de las empresas públicas al mercado financiero o a subvenciones presupuestales que les son otorgadas, y cuestionan la eficacia económica de los servicios públicos aduciendo que no podrían ofrecer un mejor servicio al menor costo.

En el marco del derecho, la crítica es doble. Por una parte, y especialmente en lo que se refiere a los servicios públicos industriales y comerciales, la realización de grandes principios básicos del servicio público -principios de igualdad, de continuidad, de adaptación- no son suficientes para brindar a los usuarios garantías reales y a veces actúa en detrimento de ellos. Se puede pensar, por ejemplo, en el cierre de escuelas de curso único, o de oficinas postales, o en supresión de estaciones y de vías férreas en zonas rurales y en regiones montañosas. Sin llegar hasta su supresión, se podría pensar igualmente en el aumento del costo de los servicios o en la posibilidad de una diferenciación de tarifas para usuarios que se encuentran en situaciones objetivamente diferentes. Así, el principio de igualdad no se opone a un tratamiento tarifario diferente para usuarios de una misma comunidad según su lugar de residencia ya sea en el centro o en zonas más alejadas.

Por otra parte, existe cierta confusión entre lo que compete al interés general y lo que compete al servicio público. El interés general tiende, según los términos del Informe del Consejo de Estado de 1999 dedicado al concepto, a ser entendido en forma cada vez más amplia por el juez y para cubrir actividades cada vez más variadas. Esta confusión concluye en una extensión indebida atribuida a la esfera pública, así como a una superposición que conduce a hablar, a la vez y al mismo tiempo, de riesgo de confiscación pública de la iniciativa privada y del riesgo de control privado del servicio público.

En lo que se refiere a la relación entre ciudadanos y usuarios, si los franceses están apegados a sus servicios públicos y reconocen la calidad de muchos de ellos, son bastante reservados sobre el funcionamiento de otros. Estas críticas son diversas: calidad insuficiente del servicio, falta de flexibilidad y de adaptación a las necesidades de los usarios, costo excesivo. Los movimientos de huelga de mucha amplitud como los que conocieron los transportes públicos parisinos en el invierno de 1995-1996, alimentaron cierto malestar contra estructuras incapaces de administrar el diálogo social sin perturbaciones mayores para los 
usuarios. Los agentes de estos servicios, al beneficiarse con un empleo garantizado, producen muchos envidiosos en un país que cuenta con más de dos millones de desempleados. De hecho, el Estado es más criticado que las presidencias y las directivas de las empresas de servicio público. De ahí la demanda, tan antigua como aguda, de una legislación relativa a los procedimientos de iniciación de conflictos sociales, como también al servicio mínimo en caso de huelga. Desde hace medio siglo, ningún gobierno se ha arriesgado a eso o ha perseverado en iniciativas al respecto. Esas críticas no impiden la existencia de una viva oposición a la privatización de los servicios públicos: riesgo de abandono de los segmentos menos rentables de la actividad considerada, o - para los segmentos prósperos una pérdida de los «derechos sociales adquiridos» (remuneración, estabilidad en el empleo, tiempo, ritmo y condiciones de trabajo; temor recurrente al «reajuste» de efectivos (planes de despido, de jubilación anticipada).

¿Son acaso inmunes a este escepticismo los agentes mismos del servicio público? Deploran una desvalorización de su rango, un ambiente poco favorable, y temen un alejamiento de los usuarios/consumidores/ciudadanos, con el que va a la par cierto eclipse del Estado.

Este conjunto de críticas lleva, sobre todo en períodos de crisis, a una protesta que pone en evidencia el carácter político - en el sentido neutro de la palabra- del «servicio público».

Por cierto, parece que estaríamos allí muy lejos del servicio público, criterio de aplicación del derecho administrativo, de la clave que explica las construcciones jurisprudenciales del Consejo de Estado. Las decenas de miles de personas que se despliegan en manifestaciones en nombre de «la defensa del servicio público» no marchan para defender los fallos Terrier, Thérond, Monpeurt, Bertin o Grimouard. Existe un nexo entre las reacciones apasionadas con respecto al servicio público y uno de los conceptos clave del derecho público: si el Lázaro jurídico resucita periódicamente, es porque es un rostro de una concepción política ambiciosa.

La crisis del Estado-Providencia, las inquietudes nacidas del Tratado de Maastricht, de la mundialización de la economía, paralelamente a los trabajos sobre la reforma del Estado, habían hecho nacer el Movimiento por una Carta de los servicios públicos. ¿El proceso al servicio público conducirá al examinado hacia la Roca Tarpeya o hacia el Capitolio? Releamos un artículo humorístico de esta época, firmado en 1995 por Georges Vedel, en el diario Le Monde: «el servicio público hace vibrar nuestros corazones. Lo defendemos en Bruselas (...); en París parece ser el único punto en común entre el gobierno y los huelguistas (...); queremos que sea inscrito en la Constitución (...)». La construcción de la afirmación es, en derecho, simple: algunas prestaciones son indispensables para la $\mathrm{Na}$ ción. Por lo tanto, no pueden ser abandonadas a las incertidumbres del mercado. Solo el Estado y las personas públicas descentralizadas pueden asegurarlas (...). Esta es por lo menos la teoría; pero en la práctica, la ley de continuidad es negada 
evidentemente; la ley de mutabilidad solo puede aplicarse para las evoluciones aceptadas por los agentes (...). Se niega a las autoridades políticas la última palabra sobre decisiones y arbitrajes, al menos, en forma de veto. ¿Cuál es la versión correcta de este vocablo ambiguo, unánimemente reverenciado? En conclusión, el decano Vedel se pregunta sobre la conveniencia de la Carta: «redactar un texto que exaltaría las bellezas del servicio público sin poner de manifiesto la realidad sería un ejercicio de dudosa utilidad (...) iY cómo dar a nuestros socios europeos una definición clara de lo que proponemos?»

Esta última pregunta nos conduce a avanzar en un análisis profundo del principal fenómeno al que debe enfrentarse el servicio público: el potente aumento de las restricciones comunitarias con miras a asegurar la libre competencia.

\section{El nuevo reparto europeo de cartas}

Si por largo tiempo la aplicación del libre juego de la competencia por parte de las instituciones comunitarias pareció ignorar las especificidades del servicio público, en un segundo tiempo ellas hicieron al respecto una mutación sensible de sus posiciones. De una voluntad de conciliación entre las exigencias de interés general y las del mercado, la política europea condujo a tomar en cuenta el servicio público y lo que él representa, como una contribución a la instalación de un modelo europeo de cohesión social y territorial.

\section{a) De la ignorancia al reconocimiento}

El derecho comunitario no se ocupa de la noción. Ella solo aparece en el artículo 73 del Tratado instituyente y solo se ocupa de las compensaciones financieras a las restricciones de servicio público de las empresas de transporte, en beneficio de otras como las de «servicio de interés general» o «de interés económico general» del artículo 86-2. Estas empresas son sometidas al conjunto de reglas del tratado, particularmente a aquellas relativas a la competencia y a aquellas que limitan la atribución de ayudas del Estado. Ellas no pueden no conformarse a estas últimas reglas a menos, por una parte, que la aplicación de las mismas haga fracasar el cumplimiento de la misión y, por otra parte, si la derogación correspondiente no afecta el desarrollo de los intercambios en forma contraria al interés de la Comunidad. En un primer tiempo, la jurisprudencia de la Corte de justicia de las Comunidades europeas se mostró bastante reacia a aceptar estas derogaciones. Después, dos importantes decisiones de la Corte, publicadas en 1993 y en 1994, 
dieron cabida a una evolución más favorable:

- la decisión del 19 de mayo de 1993, Corbeau relativa al correo belga: cierta limitación de la competencia destinada a proteger las actividades específicas rentables, disociables de la misión de interés general del Correo, podía ser admitida siempre y cuando la obligación impuesta a este servicio de interés general de asegurar actividades no rentables, implicara una compensación por medio de actividades rentables,

- la decisión del 27 de abril de 1994, Comuna de Almelo relativa a la distribución de electricidad en los Países Bajos: una cláusula de compra exclusiva prohibiendo a un distribuidor local importar electricidad es aceptada aunque sea contraria a los artículos 81 y 82 del tratado de la Comunidad europea, porque aparece como necesaria para permitir a la empresa cumplir una labor de interés general que le había sido confiada. Esta decisión admite que elementos que no tienen un carácter únicamente económico, tales como las restricciones de reglamentación y la conducción de una política de medio ambiente, pueden ser tomados en cuenta para admitir restricciones a las reglas de libre competencia

Estas decisiones parecen remitirse, en lo que se refiere a la búsqueda de criterios de servicios económicos de interés general, a criterios cercanos a los del servicio público. Ellas fueron confirmadas por la Corte de Justicia de las Comunidades europeas el 23 de octubre de 1997, Comisión c/Francia: reconoció la posibilidad de reservar un monopolio de importación y exportación para el gas y la electricidad a GDF y EDF, teniendo en cuenta misiones de interés general que les son impartidas. Así, el juez comunitario admite que pueden ser compensadas por las restricciones que pesan especialmente sobre los servicios públicos y de las que no sufren las empresas privadas. Al mismo tiempo, se consideró igualmente posible otorgar algunas ayudas públicas, como las que recibe el Correo, que resultan de una disminución igual al $85 \%$ de sus bases impositivas «debido a las restricciones de servicio al territorio nacional y de participación en el ordenamiento territorial que se impone a este explotador» (TPICE, 27 de febrero de 1997, Federación francesa de empresas de seguros; también CJCE, 25 de marzo de 1998). Ocho años después, casí día a día depués del fallo Corbeau, la Corte de justicia prolonga este razonamiento al validar la obligación para los prestatarios de servicios postales italianos que no dependen del servicio básico de contribuir a su 
financiación, mediante el pago de un derecho postal a su administrador exclusivo para permitirle la prestación del servicio «en condiciones económicas equilibradas» (CJCE, 17 de mayo 2001, TNT Traco-Poste Italiane).

Esta evolución de la Corte de Justicia remite más ampliamente a la idea según la cual «el principio de no competencia de las empresas privadas por parte de personas públicas, previsto por el fallo Cámara de Comercio al por menor de Nevers (...) es sustituido actualmente por el de igual competencia entre personas públicas y empresas privadas» (Pierre Delvolvé).

La jurisprudencia del Consejo de Estado progresa en este sentido. Juzgó, el 3 de noviembre de 1997 -Million et Marais-, que la decisión mediante la cual una autoridad pública decidía confiar a un operador una delegación de servicio público debía respetar las disposiciones de la ordenanza del 1o de diciembre de 1986, y solo sería legal a condición de no crear un abuso de posición dominante. Admitió, más recientemente, la posibilidad para una persona pública de ser candidata a la atribución de un contrato público (Aviso del CE, 8 de noviembre de 2000, Sociedad Jean-Louis Bernard Consultores), y al beneficio de algunas ayudas cuando no falsean necesariamente la competencia para la atribución del contrato (CE, 16 de octubre de 2000, Compañía mediterránea de explotación de servicios de agua; CJCE, 7 de diciembre de 2000, Arge Gewässerschutz).

La Comisión Europea terminó por adoptar una actitud que puede, en algunos casos, matizar el principio de la libre competencia, y que se traduce por dos series de iniciativas.

En primer lugar, ha hecho emerger progresivamente el concepto de servicio universal, versión mínima del concepto francés de «servicio público», pero que tiene el mérito de reconocer la existencia de prestaciones básicas, garantes de cierta forma de solidaridad social y territorial que implica el recurso al reconocimiento de «derechos exclusivos». El ejemplo de la liberalización del sector de las telecomunicaciones ilustra en derecho nacional este movimiento, con la aparición del concepto de servicio universal en la ley del 26 de julio de 1996 que transpone la directiva comunitaria de 1996.

Después, admitió el recurso al concepto de «servicio público» en derecho comunitario, que da más densidad -al menos en Francia- a la noción de servicio de interés general. Si los tratados raramente se refieren al servicio público -artículo 77 (convertido en $73 \mathrm{CE}$ ) a propósito de los transportes aéreos-, las directivas que organizan la liberalización de ciertos sectores comienzan a hacer referencia a este artículo. Así, la directiva del 19 de diciembre de 1996 sobre la liberalización en el sector de la electricidad admite que las obligaciones ligadas a la puesta en marcha de misiones de servicio público pueden ser de naturaleza tal que interpongan legalmente obstáculos a la puesta en marcha del dispositivo que esta prevé.

En su comunicación del 26 de septiembre 1996, la Comisión había admi- 
tido en substancia la posible complementariedad entre servicio de interés económico general y realización del mercado interior, poniendo en evidencia la necesidad de disociar las misiones de los servicios de interés general y el asunto de la selección de los prestatarios a los que estas misiones pueden ser confiadas. Más recientemente, en su comunicación del 20 de septiembre de 2000, la Comisión confirma la evolución de su posición al reconocer un lugar importante al servicio público, consagrado en la política europea, con la introducción en el Tratado de Amsterdam de su artículo 16 relativo a los servicios de interés económico general.

\section{b) Del reconocimiento al enriquecimiento}

La toma en cuenta de las exigencias del servicio público, como uno de los rasgos de modelo de cohesión social y territorial europeo, se hizo posible por un entorno jurídico y extra-jurídico, que no era sin embargo tan hostil como aparece en algunos escritos.

Si bien está bastante difundida la opinión de que la mayoría de los bienes y servicios suministrados en Francia por los «servicios públicos» no lo serían donde nuestros vecinos y socios europeos, no es menos cierto que los británicos no desconocen los publics services ni las utilities; los italianos no ignoran los servizi pubblici, ni los españoles los «servicios públicos», aunque estas nociones no coincidan del todo con la noción francesa de servicio público, como tampoco los conceptos alemanes de öffentlicher Dienst, o de öffentliche Wirtschaff. No obstante las diferencias entre los conceptos jurídicos, la realidad sociológica revela claramente las convergencias. Es así como el artículo 47 de la Constitución italiana prevé la posibilidad de monopolios públicos o privados para las actividades correspondientes a los servicios públicos esenciales. Así mismo, el artículo 128 de la Constitución española dispone que «la ley puede reservar al sector público los servicios esenciales, en particular en el caso de los monopolios». Aunque la ley fundamental alemana no se refiere a la noción de servicio público, menciona sin embargo las respectivas competencias de diferentes autoridades públicas para los grandes servicios de red (ferrocarriles, correo, vias acuáticas...), y reconoce la posibilidad de nacionalizar el suelo, los recursos naturales y los medios de producción. En el Reino Unido, el movimiento de privatización iniciado a principios de los años 1980 estuvo sin embargo acompañado por la promulgación de cierto número de cartas que definían los derechos de los ciudadanos-usuarios: la Carta del ciudadano, de junio de 1991 que enumera así las exigencias de un nivel definido:

- de calidad que implica disponibilidad, competencia y rapidez de acción, garantizadas por cláusulas que definen los criterios de resultados ya usuales 
en los contratos británicos;

- de transparencia en el suministro de servicios y de información sobre la existencia de diferentes operadores si el sector de la actividad es competitivo;

- de prohibición de las discriminaciones entre usuarios en función del sexo o de la raza y de obligación para los agentes del servicio de expresarse en el idioma del usuario;

- de accesibilidad suficiente al servicio y de la posibilidad de reclamo, o de reparación en caso de perjuicio.

Así mismo, el debate actual sobre los sistemas de regulación es un amplio debate europeo. Una de las paradojas, en las confrontaciones sobre la privatización de los servicios públicos, es que Francia defiende de hecho la solución liberal por lo menos para los servicios públicos de las colectividades locales, que se conceden a empresas privadas, frecuentemente en una proporción muy superior al 50\% (agua, calefacción urbana, sanidad, desechos, transportes públicos), mientras que Alemania continúa con un sistema inspirado en el socialismo municipal a través de los Stadtwerke, poco receptivos a la competencia. Y sin embargo, Alemania es considerada como más liberal y abierta al mercado que nosotros, debido a las posiciones hostiles que hemos asumido respecto a ciertas privatizaciones en el plano nacional.

Me parece que no es inadecuado destacar una «excepción francesa» en este campo. El servicio público a «la francesa», al ampliar nuestras diferencias con nuestros asociados sobre la concepción de servicio público, los aleja de ella, a pesar de que existen fundamentos para una concepción «europea»; tendremos que esforzarnos en facilitar los posibles acercamientos. Sin duda se necesitará tiempo y, sin duda, no todo país encontrará sus propias concepciones; pero así sucede en todo el campo de acción cubierto por la Comunidad.

La construcción europea está esencialmente dominada por la libertad de circulación y de intercambios (personas, capitales, bienes, mercancías) y por el juego de la competencia. Pero el Tratado de Maastricht no deja de contener cierto número de disposiciones que, al evocar una acción de la Comunidad «tendiente al fortalecimiento de su cohesión económica y social» o «de acciones expecíficas con miras a proteger la salud, la seguridad y los intereses económicos (de los consumidores)», o la contribución de la Comunidad al establecimiento y al desarrollo de redes transeuropeas, así como a la interconexión y la interoperabilidad de las redes nacionales, hacen aparecer preocupaciones que van mucho más allá del solo ideal competetitivo. Se pueden ver en estas disposiciones los jalones de servicios públicos a escala europea, o una concepción europea del servicio público.

La política de cohesión, al expresarse desde 1975 por medio de Fondos estructurales y desde 1992, por medio del Fondo de cohesión; y más especialmen- 
te, la puesta en marcha de una política regional ambiciosa y dinámica, son el testimonio de que el imperativo de solidaridad no es ignorado ni menospreciado por la construcción europea.

El Artículo 16 del Tratado de Amsterdam, adoptado en gran parte bajo la insistente presión de Francia, dispone: «Sin perjuicio de los artículos 73,86 y 87, y teniendo en cuenta el lugar que ocupan los servicios de interés económico general entre los valores comunes de la Unión, así como el papel que desempeñan en la promoción de la cohesión social y territorial de la Unión, la Comunidad y sus Estados miembros, cada uno dentro de los límites del campo de aplicación del presente tratado, velan porque estos servicios funcionen sobre la base de principios y en condiciones que les permitan cumplir sus objetivos». Se trata, por primera vez, del reconocimiento del servicio público como instrumento esencial de cohesión social y territorial de la Unión, justificando algunas derogaciones a las reglas del tratado. Pero no será posible dar pleno efecto a estas disposiciones sino con tres condiciones: no deben ser puestas al servicio de los intereses corporativos de grandes empresas públicas de diferentes países; deben estar libres de toda confusión entre la noción de servicio público y la de sector público; finalmente, deben incluir no solamente los servicios en red y los servicios públicos locales concedidos, sino también la enseñanza, la salud y la protección social.

Dentro de esta perspectiva, ha sido incluido un artículo 36 dedicado al acceso a los servicios de interés económico general en la Carta de los derechos fundamentales de la Unión, en la reunión de Niza. Previendo que «la Unión reconoce y respeta el acceso a los servicios de interés económico general tal y como está previsto por las legislaciones y las prácticas nacionales, conforme al Tratado que instituye la Comunidad europea, con el fin de promover la cohesión social y territorial de la Unión», el artículo consolida por cierto el lugar del servicio público, pero es indudable que el valor y la fuerza jurídicas de la Carta deben ser precisados. Si ella no llegare a ser apremiante para los Estados, sus principios podrían sin embargo ser tenidos en cuenta por los jueces.

Si el artículo 295 del Tratado que instituye la Comunidad precisa que «no prejuzga para nada el régimen de propiedad en los Estados miembros», la Comisión de Bruselas se matiene desafiante frente a actividades productivas de bienes o de servicios en los que el Estado ocupa un lugar preponderante: esta situación parece ser una amenaza al ejercicio del libre juego de la competencia. Esta actitud se traduce particularmente por la «transparencia», que apela a medidas de publicidad en el campo del otorgamiento de mercados públicos, y por la obligación impuesta a los Estados de comunicar a la Comisión documentos relativos a sus relaciones con las empresas públicas y la actividad de estas empresas en sus países. La razón profunda de la desconfianza comunitaria con respecto al servicio público parece residir en la idea de que el Estado o las colectividades locales tendrán, permanentemente, la tentación de hacer aplicar reglas que no 
son el derecho común a las actividades de producción y de intercambio de bienes y de servicios en el mercado: Bruselas condena, en nombre de la competencia, las desigualdades que pueden resultar, a partir del momento en que el Estado o la colectividad pública no actúan como poder público.

\section{Las evoluciones del servicio público frente al derecho comunitario}

El debate que se instituye desde hace varios años en relación con el lugar del servicio público frente a la realización del Mercado único, cristaliza cierto número de reflexiones sobre el devenir del servicio público. Si queremos identificar con precisión las perspectivas de evolución que se desprenden de la aplicación del derecho europeo, conviene previamente aclarar sus diferentes retos.

\section{Los retos presentes}

Se trata ante todo de reexaminar los lazos existentes entre el servicio público y otras nociones clave del derecho público.

Es claro que hoy el servicio público no se confunde con el monopolio de derecho o de hecho, solo que existe una coincidencia general entre las nociones de servicio público y de función pública, de servicio público y de dominio público. Cuando en el Consejo de Estado, durante los años que siguieron al final de la guerra, y después de haber agotado los contenciosos relacionados con ella -depuración, encarcelaciones arbitrarias, beneficios ilícitos, revisión de las situaciones de categorías de funcionarios y de militaresreexaminamos estas nociones clave -fui relator y después, comisario del gobierno-, nos preguntamos acerca de lo que era un contrato administrativo, el trabajo público, el área pública, lo que era el servicio público. El Consejo estuvo tentado, a instancias especialmente del Presidente Latournerie, elocuente y eficaz defensor de algunas de las ideas de la Escuela de Burdeos, de rehacer alrededor del servicio público cierta unidad del derecho administrativo, desgastado por la teoría del «bloque de competencia». En este espíritu, yo había concluido sobre los casos Bertin, Grimouard, Le Béton. El esfuerzo necesario fue estabilizador de la jurisprudencia. Pero la investigación filosófica de unidad encuentra sus límites en la infinita diversidad de los casos y yo había reconocido, en un artículo publicado después del Informe del Consejo de Estado de 1995 sobre «Servicio público, Servicios Públicos», que este no podía explicar todo el derecho administrativo, que no todo podía referirse a él. No es menos cierto que los estrechos lazos entre el servicio público y estos conceptos diferentes no han desaparecido. Y si, por ejemplo, se puede concebir que el estatuto del trabajo dentro de los servicios públicos, 
o servicios de interés económico general, utiliza a la vez el derecho público y el derecho privado, este estatuto debería tener en cuenta las restricciones deontológicas que se han tornado necesarias por el carácter del servicio empleador: continuidad, neutralidad, independencia, transparencia, responsabilidad.

Esta aclaración de los retos debe hacer una distinción entre las críticas dirigidas al servicio público como misión y las que se hacen a los servicios públicos como estructuras. Este asunto es sin duda difícil, ya que frecuentemente la existencia de una misión de servicio público implica la aparición de una estructura de gestión pública. Hay que distinguir dos elementos: el que trata de la rigidez y la pesadez de la gestión pública, y el que tiene que ver con la legitimidad de la injerencia de los poderes públicos en la esfera productiva con sus prerrogativas derogatorias del derecho común. El segundo elemento es más fundamental que el primero, ya que somete a discusión la noción misma.

Delimitemos mejor el campo del servicio público. Lo primero es analizar los riesgos del libre juego del mercado desde el punto de vista de la satisfacción óptima de las necesidades dentro de la colectividad: sastisfacción nula o insuficiente de las necesidades individuales no solucionables o de las necesidades fundamentales de la sociedad como ser colectivo - tales como el mantenimiento de la cohesión social (lucha contra la exclusión, política de ordenamiento territorial, protección de las zonas rurales o montañosas)-, o límites que se han de poner a una economía manejada por una pura lógica del mercado (agotamiento de los recursos raros, destrucción de medios).

En todo caso, no se pone en entredicho la legitimidad de una gestión bajo el signo del servicio público, de servicios tradicionales de soberanía. Si bien esa legitimidad no escapa a las impugnaciones, la misión de servicio público es admitida frecuentemente en muchos Estados para cierta protección social - más o menos amplia - y para la educación y la formación. La jurisprudencia del Consejo de Estado, frente al desarrollo de las intervenciones en estos campos toma en cuenta esta dimensión del servicio público. Es así, por ejemplo, para las acciones internacionales de estas colectividades: ha admitido la legalidad de la atribución de una beca mensual de cinco mil francos durante tres años a dos estudiantes extranjeros, de Rumania y de Polonia, para permitirles preparar un doctorado de «técnicas de punta» en la Universidad de ciencias y técnicas de Lille, cuya sede está instalada en el territorio de una comuna hermanada a las dos ciudades de donde dichos estudiantes eran originarios (CE, 28 de julio 1995, Comuna de Villeneuve d'Ascq).

Una segunda diligencia, en el plano jurídico, consiste en reflexionar sobre los lazos entre servicio público y las normas que resultan de la constitución de los tratados y de las leyes. El nacimiento progresivo de normas cons- 
titucionales y convencionales puede hacer nacer la tentación de dar lugar, en ruptura con el famoso «existencialismo jurídico» proclamado en otro tiempo, una concepción «esencialista» del servicio público. Hay que resisitir a esta tentación, ya que el servicio público -en su noción como en su campo y sus procedimientos de acción- necesita cierta plasticidad, aunque un mínimo de estabilidad en la distribución de las cargas, los roles o las competencias, es necesario para garantizar a los usuarios y a los operadores la seguridad jurídica, o la seguridad sin más, a las que unos y otros aspiran legítimamente. Creación, supresión o transformación de servicios públicos dependen normalmente de la competencia del legislador, dentro del respeto de los tratados y bajo el control de juez constitucional.

Un asunto importante queda sobre el tapete: ihasta qué punto es posible justificar los avances del servicio público en vista de consideraciones que tienen en cuenta no solamente los límites de la oferta del mercado, sino también la rentabilidad o la competividad necesaria de los operadores? El problema de la diversificación de las empresas públicas de servicio público y de sus actividades accesorias fueron objeto de un concepto del Consejo de Estado (7 de julio de 1994) a propósito de Electricidad de Francia-Gas de Francia. El concepto recordó la vigencia del principio de especialidad. Los silencios de los textos no ponen obstáculos a las actividades anexas, con tal de que se observen dos condiciones que deben llenarse acumulativamente:

- por una parte, deben ser el complemento de la actividad principal, aun cuando no sean absolutamente necesarias a esta;

- por otra parte, deben revestir a la vez un carácter de interés general y de utilidad para el establecimiento público.

Desde que se elaboró la teoría del servicio público, se han seguido de ella algunos principios fundamentales, las «leyes del servicio público», a los que el funcionamiento está sometido: igualdad, continuidad, adaptación, neutralidad y laicidad. Pero con el transcurrir de los años, la evolución económica y social, así como el desarrollo de los servicios públicos de naturaleza industrial y comercial, no dejaron de afectar el alcance y el contenido de estos principios fundamentales, suscitando nuevos interrogantes para el jurista. ¿En qué medida, por ejemplo, la tarifación diversificada que practican los grandes servicios industriales y comerciales es compatible con el principio de igualdad de los usuarios? Es el problema tratado por el concepto que el Consejo de Estado rindió el 24 de junio 1993 relativo a la tarifa experimental del TGV Norte-Europa. ¿Cómo conciliar con el principio de continuidad ya sea las supresiones de los servicios que son consecuencia del aumento de los imperativos de rentabilidad, ya sea el ejercicio del derecho de huelga, cuyo marco legislativo sigue siendo fragmentario? ¿Cómo conciliar con la libertad de los alumnos la neutralidad y la laicidad del servicio públi- 
co, en particular del servicio de la enseñanza? Recordemos aquí el problema de las «pañoletas islámicas» que dio lugar, después del concepto emitido por el Consejo de Estado el 27 de noviembre 1989, a una jurisprudencia matizada, ilustrada tanto por la decisión del 2 de noviembre 1992 Kherouaa y otros, para los musulmanes, como por las decisiones Koen y Consistorio central de los israelitas de Francia, del 14 de abril 1995, para los estudiantes israelitas. Al conciliar los principios de laicidad y de libertad de conciencia, estas decisiones juzgaron ilegales los reglamentos que dictaminan prohibiciones generales y absolutas, y establecieron que las sanciones deben ser justificadas, vez por vez, por las circunstancias de cada caso. Concretamente, los signos de pertenencia religiosa no deben revelar una voluntad de proselitismo, perturbar el orden público o el buen desarrollo de los cursos de formación.

Al lado de estos principios de contenido renovado, apareció lo que en la Carta de los servicios públicos adoptada el 18 de marzo de 1992 llamaba «principios de acción»: de participación, de transparencia y de responsabilidad, de simplicidad y de accesibilidad. Algunos implican la continuación de esfuerzos anteriores: aun si el balance de la asociación de usuarios en cuanto a la gestión de las empresas nacionalizadas o del seguro social no es siempre concluyente, subsiste sobre este punto una fuerte demanda, a la que las empresas como Electricidad de Francia, la Sociedad nacional de ferrocarriles o la Sociedad autónoma de transportes parisinos trataron de responder organizando formas de concertación. El principio de transparencia encontró su traducción jurídica con las importantes leyes del 6 de enero de 1978 llamada «informática y libertades»-, del 17 de julio de 1978, que organiza especialmente el acceso a los documentos administrativos, y del 11 de julio de 1979, que impuso en numerosos casos la motivación expresa de las decisiones administrativas.

El derecho comunitario impone igualmente a los Estados miembros y a sus colectividades públicas obligaciones precisas de transparencia, en lo que se refiere especialmente al otorgamiento de mercados. Las directivas 92/50 del 18 de junio de 1992 y 93/37 del 14 de junio de 1993, relativas a los mercados públicos de servicios y de trabajos, respectivamente, prescriben obligaciones de competitividad, y el Consejo de Estado verifica el respeto de las mismas por parte las autoridades nacionales, como lo muestran las decisiones Tête, del 6 de febrero 1998, y Comuna de Piémont de Barr, del 20 de mayo 1998. Respondiendo a este movimiento, pero principalmente a una preocupación creciente de transparencia expresada en el plano nacional, el legislador introdujo así algunas reglas que enmarcan el procedimiento de conclusión de convenios de delegación de servicio público, para asegurar una práctica competetitiva y reforzar los medios de control de las colectividades 
públicas sobre los delegatarios, a través de las leyes del 29 de enero 1993, llamada Ley Sapin y del 8 de febrero 1995, llamada Ley Barnier.

Las perspectivas de evolución del servicio público frente al derecho comunitario.

Tres parejas de nociones permiten esbozar el marco jurídico en el que éstas se inscribirían tanto en el plano comunitario como en el nacional.

\section{a. Iniciativa nacional y estrategia comunitaria}

¿Desea la comunidad europea poner en marcha una política comunitaria organizando a escala europea los grandes servicios públicos de redes? Hasta ahora el camino escogido ha sido el de directivas sectoriales de armonización de las reglas nacionales. Desde el relativo fracaso de las redes transeuropeas previstas sin embargo por el Tratado de Maastricht pero que no recibieron los medios financieros necesarios para una realización significativa, podría dudarse. La paradoja de esta situación se encuentra en el hecho que, al mismo tiempo, los proyectos transnacionales son numerosos (extensión del TGV Norte, proyecto del TGV Este, línea férrea Lyon-Turín...). En todo caso, una política comunitaria de servicios en red debe estar acompañada de una aclaración del marco jurídico comunitario para poner en práctica un verdadero desarrollo de estos servicios en la línea de las disposiciones del artículo 16 del Tratado de las Comunidades europeas. Hay que definir, ante todo, la especificidad de los servicios de interés general en relación con las otras actividades de producción de bienes y de servicios. Para aclarar la situación y acrecentar la seguridad jurídica de los actores, especialmente públicos confrontados a las dificultades de aplicación de las reglas de competencia, es necesario identificar más claramente las nociones de servicio universal, de servicio de interés general, de servicio económico de interés general, o servicio público, a menos que se encuentre un concepto único y federador, tan buscado en Francia.

\section{b. Eficacia económica y cohesión social}

El artículo 16 del Tratado de la Comunidad europea, eventualmente modificado y completado, permitirá una mejor distinción dentro de los servicios de interés general. Desde hace algunos años, en Europa se han manifestado inquietudes en cuanto al destino deparado por la Comisión y la Corte de justicia de las Comunidades europeas a los servicios sociales (seguro de enfermedad, pensiones...). La preocupación de eficacia económica y de cohesión social a menudo son potencialmente contradictorias, como lo muestran los problemas de la tarifación. El reto aquí es seguramente evitar el desmantelamiento siste- 
mático de estrategias de distribución equitativa: la amenaza puede venir tanto de las instancias comunitarias como del juez nacional. El Consejo de Estado, por ejemplo, ha proscrito toda financiación de un servicio público deficitario por medio de tarifas percibidas en razón de un servicio excedente de la misma colectividad (ley del 30 de julio de 1996, Ville de Saint Etienne). Pero puede haber también compensación dentro de un mismo servicio. Por extraña que parezca la aplicación de este sistema en relación con la búsqueda del justo precio correspondiente al costo real -condición de su transparencia-, su desaparición provocaría tales consecuencias políticas, económicas y sociales, que se debería pensar en mecanismos que pudieran suplirla y en su financiación. iEn qué medida, sobre todo, solicitaríamos al contribuyente la diferencia entre lo que cuesta el servicio para ciertos usuarios y el precio real que ellos pagan? En esta perspectiva, para los servicios de compensación tarifaria, el reconocimiento en el Tratado de posibilidades de compensación que podría incluirse en el artículo 16, constituiría un avance positivo al eximir a la Unión Europea de participar en el desmantelamiento de un modelo social que prevalece en una mayoría de sus Estados miembros.

\section{c. Participación y territorios}

La elección entre las colectividades territoriales del mejor nivel (tenemos demasiadas en Francia) de intervención de operadores y de reguladores que ofrece la posibilidad efectiva de participaciones a los usuarios, responde más a consideraciones políticas que a datos técnicos. Es difícil de encontrar la solución en el plano nacional. Según la definición de la limitación de poderes considerados como subsidíarios en las competencias comunitarias y nacionales, Europa puede asociarse a colectividades territoriales para proyectos que se inscriben en las acciones de la Comunidad y en los programas de políticas europeas, si son escogidos, después de una selección, y obtienen una ayuda, completando eventualmente acciones nacionales, regionales o locales. Pero se impone una gran vigilancia para no cruzar ayudas que harían perder a los proyectos su cohesión y diluirían la responsabilidad de las colectividades participantes.

\section{Conclusión}

Sin duda debemos admitir que hoy solo deben colocarse bajo el signo del servicio público las actividades «indispensables a la realización y al desarrollo de la interdependencia social», para retomar la expresión con la cual Léon Duguit definía en 1928 el campo natural del servicio público.

Pero el adjetivo «indispensable» dejaba un amplio margen de interpretación y de evolución. Si sabemos muy bien que el Estado no puede ser una 
inmensa cooperación de servicios públicos que asegure la coherencia de la sociedad, me resisto aún más a definirlo -por oposición- como el único titular de la violencia, por lo menos de la violencia legal. Porque el servicio público nos remite al concepto que nos hacemos del Estado. No podemos, tampoco, precisamente cuando emergen la sociedad civil en el plano nacional, y las organizaciones no gubernamentales en el plano mundial, hacer del Estado el único garante del bien común, o del interés general. El Estado es todo eso a la vez y participa en todas esas finalidades, al precio, sin lugar a dudas, de caer en contradicciones y de cometer fallas en su acción. Si debe ser «modesto» es porque él puede y debe mensurar de todas esas nuevas misiones de conducta -que no deberían ser reducidas al poder y al servicio- y de acompañamiento de los pueblos que quieren vivir y vivir su vida dentro de una sociedad y un mundo nuevos. Su integración en la Comunidad Europea obliga al Estado a compromisos o, lo que es mejor, si es posible, a síntesis para conjurar la inseguridad de comportamientos y del derecho mismo que nos amenazan en este difícil camino. La integración nos exige a todos, ciudadanos y Estados actores de la Comunidad, a asumir nuestras responsabilidades. No temeremos, como nuestros ancestros galos, que «el cielo caiga sobre nuestras cabezas», si nuestra acción es hábil, eficaz para hacer prevalecer, en la globalización de los problemas, concepciones que nos resulten aceptables y que eviten un desgarramiento del pacto social cuya noción de servicio público es uno de los elementos fundadores que no se borra fácilmente de la memoria y del subconciente colectivos. 